\title{
Receptor Binding by Cholera Toxin B-Subunit and Amino Acid Modification Improves Minimal Peptide Immunogenicity
}

\author{
Andreas Boberg, ${ }^{1,2}$ Alexandra Stålnacke, ${ }^{3}$ Andreas Bråve, ${ }^{1}$ Jorma Hinkula, ${ }^{4}$ \\ Britta Wahren, ${ }^{1}$ and Nils Carlin ${ }^{3}$ \\ ${ }^{1}$ Department of Microbiology, Tumor and Cell Biology, Karolinska Institute, 17182 Stockholm, Sweden \\ ${ }^{2}$ Division of Education and Research administration, Mälardalen University, P.O. Box 883, 72123 Västerås, Sweden \\ ${ }^{3}$ Etvax AB, Gunnar Asplunds Alle 16, 17163 Solna, Sweden \\ ${ }^{4}$ Institution of Clinical and Experimental Medicine, Linköping University, 58183 Linköping, Sweden \\ Correspondence should be addressed to Andreas Boberg, andreas.boberg@mdh.se
}

Received 12 April 2012; Accepted 20 May 2012

Academic Editors: H. Hashimoto and I. Kim

Copyright ( $) 2012$ Andreas Boberg et al. This is an open access article distributed under the Creative Commons Attribution License, which permits unrestricted use, distribution, and reproduction in any medium, provided the original work is properly cited.

\begin{abstract}
We increase our understanding of augmenting a cellular immune response, by using an HIV-1 protease-derived epitope ( $\mathrm{PR}_{75-84}$ ), and variants thereof, coupled to the C-terminal, of the B subunit of cholera toxin (CTB). Fusion proteins were used for immunizations of HLA-A0201 transgenic C57BL/6 mice. We observed different capacities to elicit a cellular immune response by peptides with additions of five to ten amino acids to the PR epitope. There was a positive correlation between the magnitude of the elicited cellular immune response and the capacity of the fusion protein to bind GM-1. This binding capacity is affected by its ability to form natural pentamers of CTB. Our results suggest that functional CTB pentamers containing a foreign amino acid-modified epitope is a novel way to overcome the limited cellular immunogenicity of minimal peptide antigens. This way of using a functional assay as readout for improved cellular immunogenicity might become highly valuable for difficult immunogens such as short peptides (epitopes).
\end{abstract}

\section{Introduction}

Combinations of antiretroviral drugs are still the only effective approach to delay the progression to acquired immunodeficiency syndrome (AIDS) in HIV-1 infected patients. Due to the ability of the virus to introduce and tolerate mutations within the viral proteins, resistance to antiretroviral drug treatment may occur [1-3]. Approximately $10 \%$ of the newly diagnosed HIV positive patients, naïve to drug treatment in Europe, are infected with drug-resistant virus [4,5]. Effective antiretroviral drug regimens are available; however, to a lesser extent in resource-poor countries than in the industrial parts of the world, whereby a vaccine strategy working in synergy with drug treatment would be beneficial. Previous work has shown that it is possible to induce a cellular immune response against mutated HIV-related epitopes by immunizing with such an epitope [6-8]. The use of short peptides as vaccine candidates is an interesting approach; however, there are immunogenicity problems using only the naked peptide as an immunogen. In order to increase the immunogenicity of short epitopes, novel approaches are needed. We have previously tested the approach of linking peptide to erythrocytes and using these cells as a vessel for transport of peptides to immune cells, as the erythrocytes were treated to be recognized as old by the cells [6]. Despite an increased response, the overall magnitude of the response was weak. We have also previously investigated the use of the B subunit of Cholera toxin (CTB) from the bacterium Vibrio cholerae as a carrier of an HIV-derived epitopes [9]. In the earlier work, we focused to target the immune response to HIV reverse transcriptase since that protein is heavily mutated during the viral life cycle, especially under suboptimal drug treatment. In the present study, an approach using modulated CTB as carrier of HIV derived protease peptides was initiated. The focus was set to HIV protease-(PR) derived epitopes already containing amino 
acid changes related to drug resistance. CTB has been shown to enable the induction of an antibody response to epitopes carried by full proteins [10-12], but less is known of its ability to augment cellular immune responses to short epitopes [9]. In that earlier work, pentamers of rCTB spontaneously formed. Shifting the setting to target short peptides as a load to the CTB molecule, it was hypothesized that we might augment immunoreactivity to the short peptide.

Interestingly, there seemed to be a good correlation between a theoretical alpha amphipathic region in the Cterminal region and the ability of the constructs to form pentamers.

\section{Material and Methods}

2.1. Epitope Selection. An epitope from the HIV protease protein corresponding to amino acids 75-84 was selected for genetic conjugation to the B-subunit of the cholera toxin. The reason for this selection is that in an HIV infected individual it may become possible to immunize against development of drug resistance $[7,8]$. The epitope was altered to include mutations, either the I84V mutation alone or the V82F and $184 \mathrm{~V}$ mutations simultaneously. These epitopes are restricted to human leukocyte antigen (HLA) A0201 binding [7, 13], and naturally immunogenic in HIV-1 infected patients [13-15].

2.2. Production of Fusion Protein. Forward and reverse oligonucleotides corresponding to amino acid sequences 75-84, 75-89, and 75-94 from HIV protease harboring the mutations $184 \mathrm{~V}$ and/or V82F were purchased from SGS DNA, Köping, Sweden. The oligonucleotides were made to encode overhangs corresponding to HindIII and Kpn1 restriction enzyme sites, to enable cloning into an expression vector [16]. This vector encodes the CTB under the control of a tac promoter $[12,16]$. DNA-sequencing, and control cleavage using $\mathrm{HpaI}$ or BanII confirmed correct DNA sequences of the constructs. The constructs were electroporated into BL21 bacteria (Invitrogen) and expression of the fusion proteins was induced by isopropyl $\beta-\mathrm{D}-1-$ thiogalactopyranoside (IPTG; Sigma Aldrich, Stockholm, Sweden) stimulation for 3 hours at a concentration of $1 \mathrm{mM}$. Fusion proteins were released from inclusion bodies using Bugbuster lysis (Novagen, Nottingham, United Kingdom) or by disruption of the BL21 cells using the constant cell disruption system (Constant Systems Limited) at $1.7 \mathrm{kBar}$.

2.3. Fusion Protein Characterization. The fusion proteins, hereafter called rCTB-PR ${ }_{75-94} \mathrm{I} 84 \mathrm{~V}, \mathrm{rCTB} \mathrm{PR}_{75-94} \mathrm{~V} 82 \mathrm{~F} /$ $\mathrm{I} 84 \mathrm{~V}, \mathrm{rCTB}-\mathrm{PR}_{75-89} \mathrm{I} 84 \mathrm{~V}$, and $\mathrm{rCTB}-\mathrm{PR}_{75-84} \mathrm{I} 84 \mathrm{~V}$, were purified with either affinity chromatography and/or by using an ion-exchange column followed by affinity chromatography. The integrity of the protein was analyzed by $\mathrm{N}-$ and C-terminal sequencing, as well as by electrospray-massspectroscopy at the Protein Analysis Centre, Karolinska Institute, Sweden. Gel electrophoresis followed by silver staining verified the purity and configuration of the proteins. Biologic activities (GM-1 binding) of the CTB moiety of the fusion proteins were analyzed using the Biacore system. Theoretical analysis of the secondary structure of the fusion protein was done using the DNAStar Lasergene 8.1 program Protean (Bioinformatics Pioneer DNAStar, Inc., WI). The software predicts the secondary structure characteristics based on relevant method; in this case, the Eisenberg method [17] selected.

2.4. Immunizations. Groups of HLA-A0201 transgenic C57BL/6 mice [18], 3-8 mice per group, were housed and handled according to animal care guidelines at the Karolinska Institute, Sweden, with the approval of the local ethical animal welfare committee. Four immunizations were given subcutaneously at the base of the tail at a monthly interval. A total dose of $50 \mu \mathrm{g}$ immunogen in PBS was given in each immunization. The animals received one of the fusion proteins rCTB$\mathrm{PR}_{75-94} \mathrm{I} 84 \mathrm{~V}$, rCTB-PR $75-94 \mathrm{~V} 82 \mathrm{~F} / \mathrm{I} 84 \mathrm{~V}$, rCTB-PR ${ }_{75-89} \mathrm{I} 84 \mathrm{~V}$, or $\mathrm{rCTB}-\mathrm{PR}_{75-84} \mathrm{I} 84 \mathrm{~V}$. Additional groups of mice were immunized with the mixture of $\mathrm{rCTB}$ and one of the two peptides $\mathrm{PR}_{75-84} \mathrm{I} 84 \mathrm{~V}$ or $\mathrm{PR}_{75-84} \mathrm{~V} 82 \mathrm{~F} / \mathrm{I} 84 \mathrm{~V}$, rCTB only, the individual peptides $\mathrm{PR}_{75-84} \mathrm{I}_{84 \mathrm{~V}}$ or $\mathrm{PR}_{75-84} \mathrm{~V} 82 \mathrm{~F} / \mathrm{I} 84 \mathrm{~V}$ only, or were left untreated.

2.5. Serum Collection and Cell Preparations. Two weeks following each of the immunizations, individual blood samples were taken. Sera were individually collected and stored at $-20^{\circ} \mathrm{C}$ until use. The peripheral blood mononuclear cells (PBMCs) from group-wise-pooled blood were separated by Ficoll-Paque gradient (GE Healthcare, Uppsala, Sweden). After washing, the PBMCs were resuspended in $1 \mathrm{~mL}$ RPMI medium containing $1 \%$ PEST, $2 \mathrm{mM}$ L-glutamine, $1 \%$ HEPES, and $20 \%$ fetal calf serum (referred to as RPMI plus medium).

At the end of the studies, animals were sacrificed by cervical dislocation, and the spleens and serum harvested. Spleens were individually mashed in PBS, and the cell suspensions were separated by Ficoll-Paque gradient and resuspended in $2 \mathrm{~mL}$ RMPI plus medium. Cells (PBMCs and splenocytes) were diluted to a final concentration of 2 million cells per $\mathrm{mL}$. One hundred $\mu \mathrm{L}$ of the cell suspension was added per well in the polyvinyldifluoride (PVDF) membrane 96-well microtiter ELISpot plate.

2.6. IFN- $\gamma$ ELISpot. IFN- $\gamma$ ELISpot was performed as described by the manufacturer (Mabtech AB, Nacka, Sweden). Briefly, following anti-IFN- $\gamma$ antibody coating, plates were washed and blocked with RPMI complete medium (RPMI medium containing 1\% PEST, $2 \mathrm{mM} \mathrm{L}$-glutamine, $1 \%$ HEPES, and $10 \%$ FCS). Per well, 200,000 mononuclear cells were added and were stimulated over night with $1 \mu \mathrm{g}$ of antigen. Detection of spots was done using alkalinephosphate conjugated antibodies. Substrate was added, and color reaction proceeded for 10 minutes at room temperature and was stopped by extensive wash in tap water. Plates were let to dry and read using the AID ELISpot reader system. Cutoff of responding animals was set to $>50$ spot-forming cells (SFC)/million cells (PBMCs or splenocytes), and was 
calculated by subtracting the background response to the HLA-A2 restricted control peptide SLYNTVATL from HIV1 p17 Gag.

2.7. GM-1 Binding Property of the Fusion Proteins. A carboxymethyldextran (CM5; Biacore, Uppsala, Sweden) sensor chip was docked to the BIACORE2000 machine (Biacore, Uppsala, Sweden) and flowed with HBS-EP buffer (10 mM HEPES $\mathrm{pH} 7.4,0.15 \mathrm{M} \mathrm{NaCl}, 3 \mathrm{mM}$ EDTA, and $0.005 \%$ Surfactant P20). GM-1 was immobilized on the chip by direct injection, followed by blocking in 1\% BSA in HBS-N (10 mM HEPES pH 7.4, 0.15 M NaCl). The samples (rCTB standards, controls, and rCTB-HIV fusion protein) were automatically injected to the chip. The amount of bound $\mathrm{rCTB}$ was measured as resonance units (RU) and translated into rCTB concentration through the standard curve constructed from known concentrations of rCTB standard (ranging from 2.37 to $0.0925 \mu \mathrm{g} / \mathrm{mL}$ rCTB). GM-1 binding capacities of the fusion proteins were calculated as percent binding in relation to rCTB standard, using the formula

$$
\left(\frac{\text { bound fusion protein }}{\text { maximal bound rCTB protein }}\right) \times 100 \text {. }
$$

2.8. Statistics. Statistical comparisons between groups were performed using the nonparametric Kruskal-Wallis test to detect differences between groups for the ELISpot results. At significant differences, individual groups were compared using the Mann-Whitney $U$ test. A two-tailed analysis was performed with the criteria of a significant level of $95 \%$. All calculations were done using the GraphPad Prism v4.02 software (GraphPad Software Inc.). Correlation comparisons were performed with Spearman rank test by correlating binding capacities to GM-1 for the fusion proteins with the individual ELISpot result per mouse using Statistica 8.0 software (StatSoft Inc.).

\section{Results and Discussion}

The importance of cytotoxic T cells in HIV infection as well as in SIV/SHIV infection in nonhuman primates is well established [19-24]. Additionally, the potency of CTB as a carrier of protein or peptide for the induction of a humoral immune response has been previously proven [1012]. However, the capacity of CTB as a carrier for small peptides [9] has not been fully explored. In the present study, we linked an HIV-1 protease epitope to CTB (schematically viewed in Figure 1), which affected the molecular structure of CTB, and tested the immunogenic potency of the resulting fusion protein. The HIV protease peptide was chosen, since it has clinical potential to prevent resistance to certain drug treatments $[7,8]$.

Under native conditions, we found that rCTB$\mathrm{PR}_{75-89} \mathrm{I} 84 \mathrm{~V}$, rCTB-PR $75-94 \mathrm{I} 84 \mathrm{~V}$, and rCTB-PR ${ }_{75-94} \mathrm{~V} 82 \mathrm{~F} /$ I84V fusion proteins mainly formed pentamers (Figure 2,

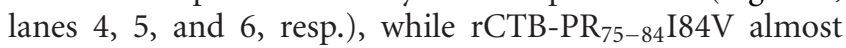
exclusively remained in a monomeric configuration (Figure 2, lane 3). The molecular weights of the expressed fusion proteins agreed with the theoretical weight of approximately $13.3 \mathrm{kDa}$ (varying from $12.7-13.8 \mathrm{kDa}$ ) under denatured conditions, and molecular weights of approximately $66.5 \mathrm{kDa}$ (varying from 63.5 to $69 \mathrm{kDa}$ ) were found for the pentameric proteins under native conditions (Figure 2, lanes 4, 5, and 6). Initial experiments with the monomeric fusion protein showed low immunogenicity. The comparison in the natural structure of that fusion protein in relation to the fusion protein used previously [9] made us construct fusion proteins having a longer epitope attached to the CTB moiety but that retained the natural ability to form pentamers. The individual sequences of the fusion proteins analyzed in the Protean program revealed for all of them that a theoretical alpha amphipathic region scored for the C-terminal part of the protein in at least one algorithm correlated with ability to form pentamers, whereas the original epitope without additional amino acids did not form pentamers and did not score an alpha amphipathic region, Figure 3. To investigate the potency of these new fusion proteins to induce and augment a cellular immune response to the conjugated epitope, HLA-A0201 transgenic C57BL/6 mice were immunized (Table 1), and the epitope-specific immune responses were analyzed.

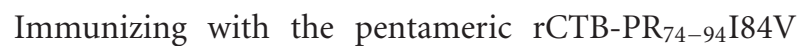
induced significantly higher responses $(P=0.01)$ than the monomeric rCTB-PR ${ }_{75-84} \mathrm{I}_{84}$ Vor the mixture of $\mathrm{rCTB}$ and peptide (Figures $4(\mathrm{a})-4(\mathrm{c})$, group/s A versus E-H). Immunization with the peptide alone did not induce detectable cellular responses to either epitope (Figures $4(\mathrm{a})-4(\mathrm{c})$, groups $G$ and $H)$. Interestingly, when comparing the biological property of the CTB moiety of the fusion proteins by measuring binding to GM-1 receptor (Table 2), we observed that the ability to interact with GM-1 correlated with immunogenicity (Figures $4(\mathrm{a})-4(\mathrm{c})$, groups A-C). A positive correlation was seen between binding to GM-1 and induced immune response against the $\mathrm{PR}_{75-84} \mathrm{I} 84 \mathrm{~V}$, and the wild type $\mathrm{PR}_{75-84}$ epitopes $(r=0.47, P=0.001$, and $r=0.4, P=0.01$, resp.). No correlation between binding capacity and induced immune response could be observed against the doubly mutated $\mathrm{PR}_{75-84} \mathrm{~V} 82 \mathrm{~F} / \mathrm{I} 84 \mathrm{~V}$ epitope.

Taken together, our results imply that the capacity of CTB fusion proteins to be in a pentameric configuration, which is required for GM-1 binding, is crucial in order to induce cellular immune response against the conjugated epitope. It has been shown that conjugation of antigen to CTB enhances the transport of the antigen over mucosal surfaces and an increased delivery of the antigen to macrophages and dendritic cells $[25,26]$. Moreover, a retrograde transport of the toxin-receptor complex via the Golgi compartment to the endoplasmic reticulum (ER) follows upon binding of CTB to GM-1 [27-29]. Such targeted ER transport will potentially enhance the chance of peptide/antigen loading onto HLA class I molecules. This possibly explains why the conjugation of an epitope to pentameric CTB enhances the immunogenicity of the antigen, and why immunization with a fusion protein unable to bind GM-1 are less effective in stimulating a cellular immune response [11,30]. Another mechanism that may play a role in the enhancement of 


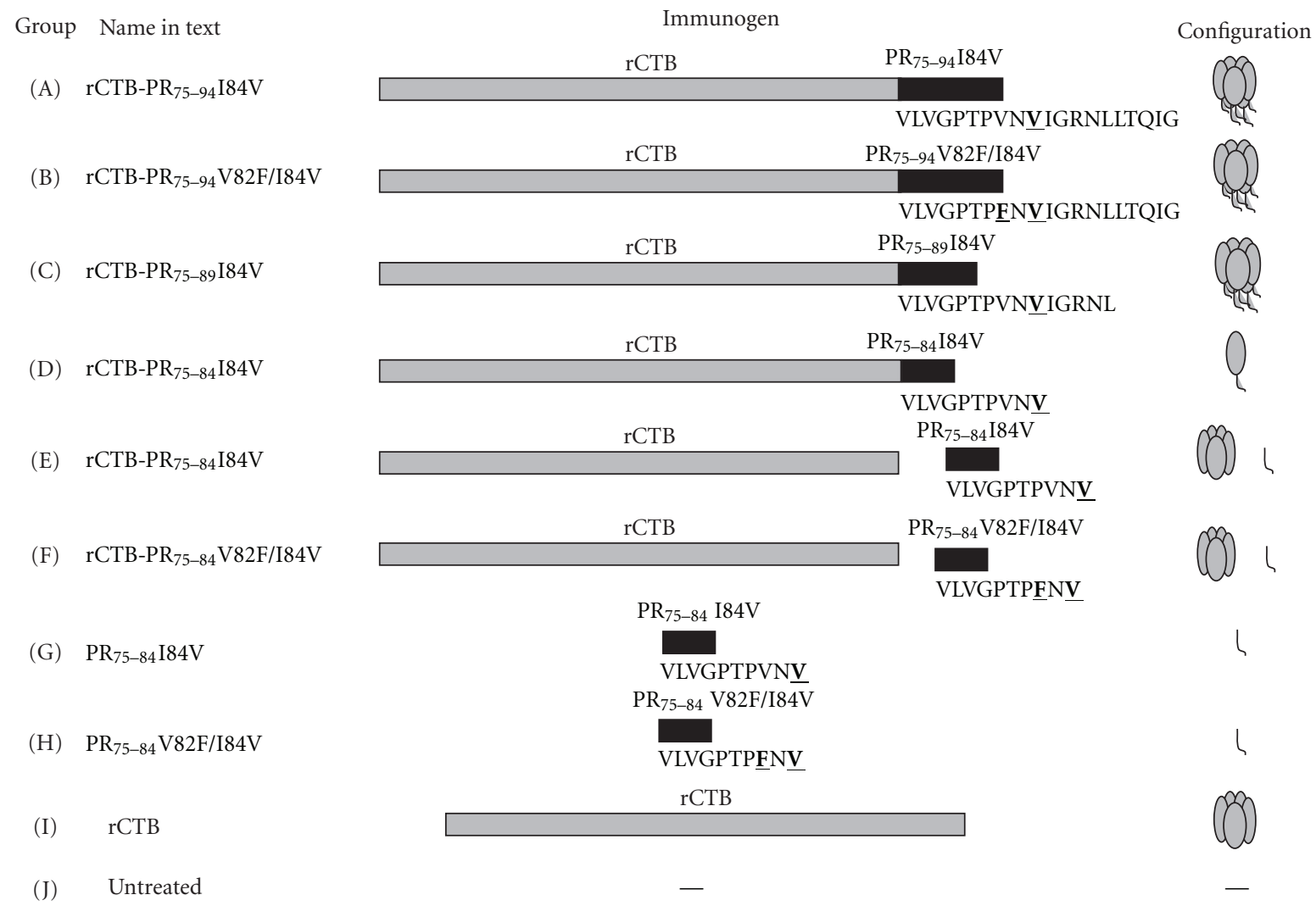

FIGURE 1: (a)-(i) Schematic picture of the immunogens.

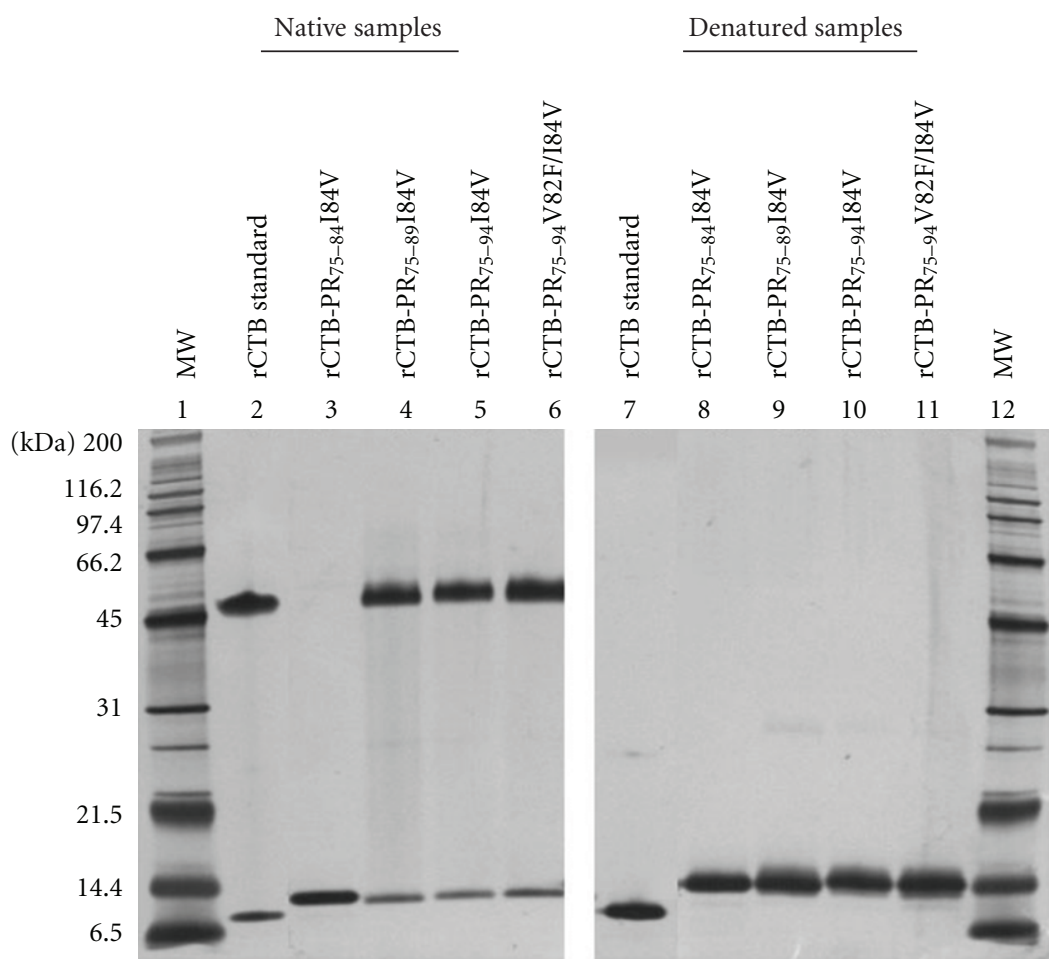

FIGURe 2: Silver staining of rCTB-protease fusion proteins. Purified protein was run on SDS-PAGE gels and silver stained. Lanes 1-6: native samples. Lanes 7-12: denatured samples. Lanes 1 and 12: see Blue 2 molecular weight standard, Lanes 2 and 7: rCTB standard, Lanes 3 and

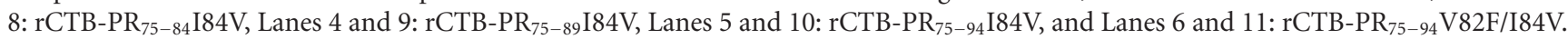




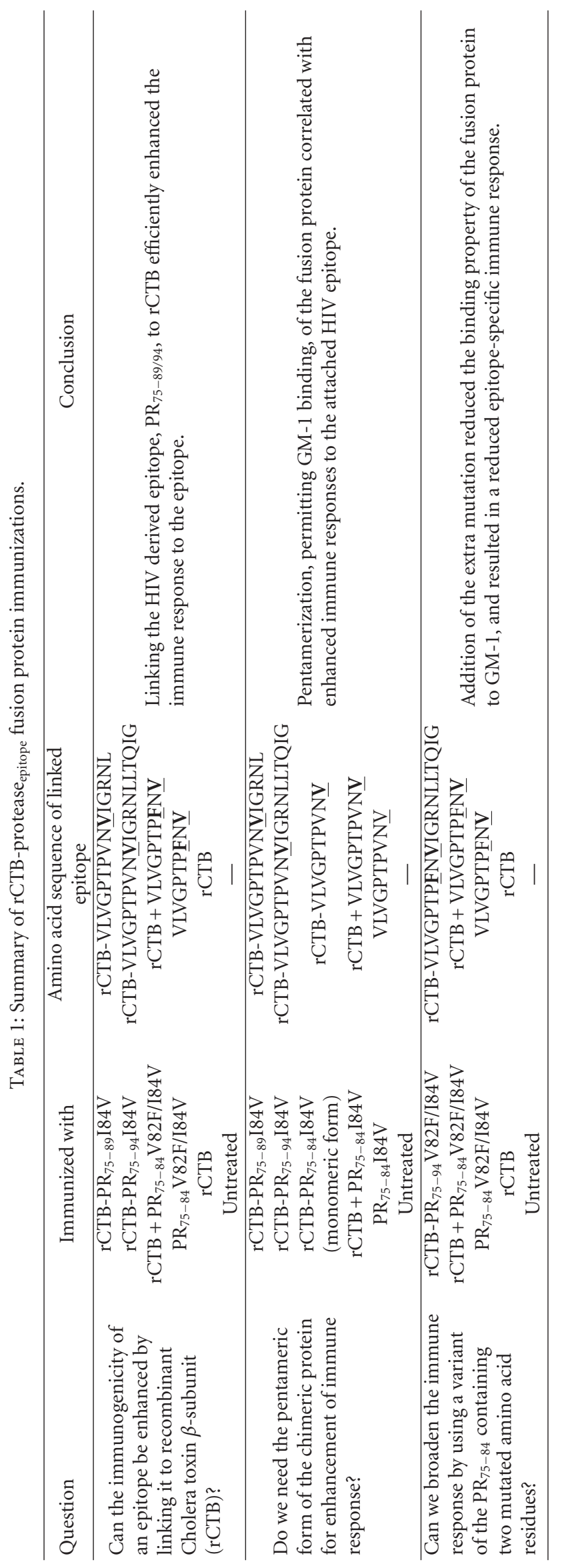


TABLE 2: Receptor binding property of the $\mathrm{CTB}^{\mathrm{a}}$ moiety of fusion proteins relative to the binding of unmodified CTB.

\begin{tabular}{lcccc}
\hline Group & Fusion protein & Maximal binding & Actual binding & Percent binding $^{\mathrm{b}}(\%)$ \\
\hline A & CCTB-PR $_{75-94} \mathrm{I} 84 \mathrm{~V}$ & $0.79 \mathrm{mg} / \mathrm{mL}$ & $0.79 \mathrm{mg} / \mathrm{mL}$ & 100 \\
B & rCTB-PR $_{75-94} \mathrm{~V} 82 \mathrm{~F} / \mathrm{I} 84 \mathrm{~V}$ & $0.86 \mathrm{mg} / \mathrm{mL}$ & $0.64 \mathrm{mg} / \mathrm{mL}$ & 74 \\
$\mathrm{C}$ & $\mathrm{rCTB}^{-P_{75-89} \mathrm{I} 84 \mathrm{~V}}$ & $0.81 \mathrm{mg} / \mathrm{mL}$ & $0.75 \mathrm{mg} / \mathrm{mL}$ & 93 \\
$\mathrm{D}$ & rCTB-PR $_{75-84} \mathrm{I} 84 \mathrm{~V}$ & $0.80 \mathrm{mg} / \mathrm{mL}$ & $0 \mathrm{mg} / \mathrm{mL}$ & 0 \\
\hline
\end{tabular}

${ }^{a}$ CTB: Cholera toxin B subunit.

$\mathrm{b}$ (bound fusion protein/maximal bound $\mathrm{rCTB}$ protein) $* 100 \%$.
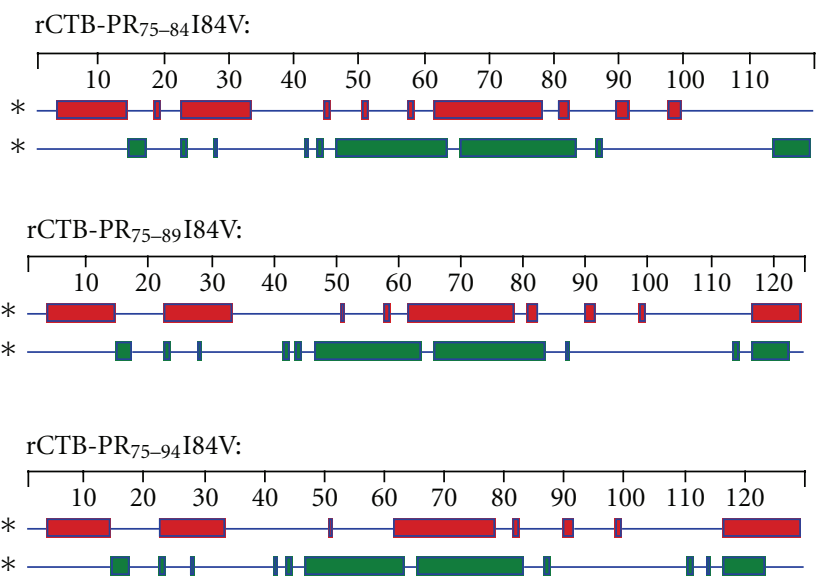

- Alpha, amphipathic regions-Eisenberg

- Beta, amphipathic regions-Eisenberg

Figure 3: Theoretical prediction of the secondary structure characteristics of the fusion proteins based on the Eisenberg method.

the immune response following administration of the CTBfusion proteins is the induction of an inflammatory response by CTB [31]. This theory is supported by our findings that the monomeric variant of the fusion protein and the mixture of rCTB and free peptide induced similar magnitudes of immune responses against the protease-derived peptides, whereas injecting the free peptide alone did not stimulate an immune response (Figure 4, groups D-H).

To investigate the capacity to induce an epitope-specific memory response following immunization with the fusion proteins, we introduced a four-month interruption in the immunization protocol between a third and fourth immunization. The response was measured following three immunizations with $\mathrm{rCTB}-\mathrm{PR}_{75-94} \mathrm{I} 84 \mathrm{~V}$ (a response of 223 SFC $/ 10^{6}$ PBMC, data not shown). During the four-month interruption of the immunization protocol, the level of the response was reduced to $50 \%$ of the original level. However, the late fourth immunization at week 28 resulted in a rapid anamnestic response (578 SFC/ $10^{6} \mathrm{PBMC}$ ), indicating that an immunological memory was induced by the initial three immunizations.

Immunization with the rCTB-PR fusion proteins did induce immune responses against not only the epitope variant found in the proteins but also against similar $\mathrm{PR}_{75-84}$ epitope variants $\left(\mathrm{PR}_{75-84}\right.$ wild type and $\mathrm{PR}_{75-84} \mathrm{~V} 82 \mathrm{~F} / \mathrm{I} 84 \mathrm{~V}$;
Figures 4(b)-4(c)). The magnitude of the response was found to be equal against the epitope in the fusion proteins (I84V) and the wild-type epitope (Figures 4(a) and 4(c)), whereas a lower response was in general measured against the double mutant epitope (V82F/I84V, Figure 4(b)). The latter was still true even when we introduced the additional V82F mutation to the protease epitope of $\mathrm{rCTB}-\mathrm{PR}_{75-94} \mathrm{~V} 82 \mathrm{~F} / \mathrm{I} 84 \mathrm{~V}$. A possible explanation for this may be that the additional mutation reduced the binding capacity of the fusion protein to GM-1 from $100 \%$ to $74 \%$, Table 2 . Moreover, knowledge that the Tcell receptor (TCR) recognition is associated with the central amino acids of the epitope presented by the human leukocyte antigen of class I [32] suggests that the minor difference between the wild type $\left(\mathrm{PR}_{75-84}\right)$ and the singly mutated epitope $\left(\mathrm{PR}_{75-84} \mathrm{I} 84 \mathrm{~V}\right)$, having the mutation at the edge of the epitope should not directly affect TCR recognition of those epitopes. Therefore, it is possible that the same T-cell clone could recognize both the $\mathrm{PR}_{75-84}$, and $\mathrm{PR}_{75-84} \mathrm{I} 84 \mathrm{~V}$ epitopes. Such an explanation supports our finding that we could measure equal magnitudes of cellular immune responses against these two epitope variants after immunization with fusion proteins expressing the $\mathrm{PR}_{75-84} \mathrm{I} 84 \mathrm{~V}$ epitope. However, the additional mutation (V82F) in $\mathrm{PR}_{75-84} \mathrm{~V} 82 \mathrm{~F} / \mathrm{I} 84 \mathrm{~V}$, located more to the central part of the epitope, possibly negatively affected the interaction with the TCR.

\section{Conclusion}

When the CTB molecule was linked to peptides extended by five or ten amino acids downstream, the CTB-peptide complex readily formed pentamers. Even though the added amino acids buried the epitope of interest within a longer (app. 20 amino acids long) stretch of amino acids, it still was possible to elicit an immune response to the epitope of interest. Thus, we show that the key issue of using CTB as a carrier molecule for augmenting the cellular response to an epitope is to retain the natural pentameric structure of CTB. This structure seems to be more affected by the amino acid composition of the epitope of interest than of the length of the epitope attached. It was possible to induce cellular immune responses against the short HIV-1 protease epitope within a longer stretch of amino acids as long as the CTB molecule allowed forming pentamers. This knowledge is important since it provides a tool to evaluate the potential of a fusion protein including CTB as a carrier. Consistently throughout the study, the highest epitope-specific immune response was observed following immunization with rCTB$\mathrm{PR}_{75-94} \mathrm{I} 84 \mathrm{~V}$. This fusion protein contained a 20-mer region 
Response to: $\quad$ VLVGPTPVNV, $\mathrm{PR}_{75-84} \mathrm{I} 84 \mathrm{~V}$

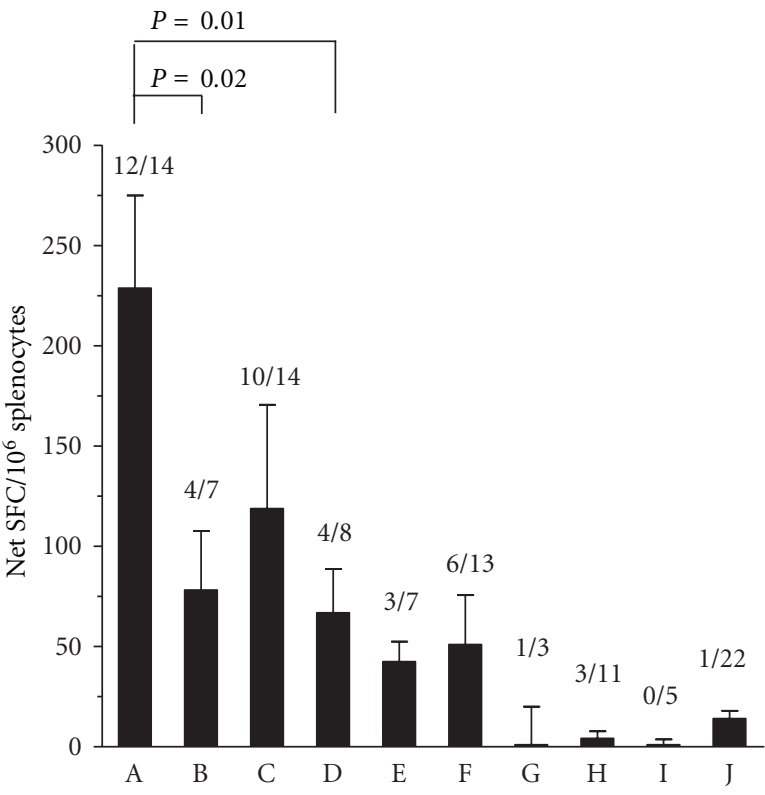

\begin{tabular}{|c|c|c|}
\hline Group & Immunogen & Type of immunogen \\
\hline (A) & rCTB-PR $75-94$ I84V & Fusion protein \\
\hline (B) & $\mathrm{rCTB} \mathrm{PR}_{75-94} \mathrm{~V} 82 \mathrm{~F} / \mathrm{I} 84 \mathrm{~V}$ & Fusion protein \\
\hline (C) & rCTB-PR ${ }_{75-89} \mathrm{I} 84 \mathrm{~V}$ & Fusion protein \\
\hline (D) & rCTB-PR ${ }_{75-84} \mathrm{I} 84 \mathrm{~V}$ & Fusion protein \\
\hline (E) & $\mathrm{rCTB}+\mathrm{PR}_{75-84} \mathrm{I} 84 \mathrm{~V}$ & Mixed \\
\hline$(\mathrm{F})$ & $\mathrm{rCTB}+\mathrm{PR}_{75-84} \mathrm{~V} 82 \mathrm{~F} / \mathrm{I} 84 \mathrm{~V}$ & Mixed \\
\hline (G) & $\mathrm{PR}_{75-84} \mathrm{I} 84 \mathrm{~V}$ & Peptide alone \\
\hline$(\mathrm{H})$ & $\mathrm{PR}_{75-84} \mathrm{~V} 82 \mathrm{~F} / \mathrm{I} 84 \mathrm{~V}$ & Peptide alone \\
\hline (I) & $\mathrm{rCTB}$ & Protein alone \\
\hline$(\mathrm{J})$ & Untreated & - \\
\hline
\end{tabular}

(a)
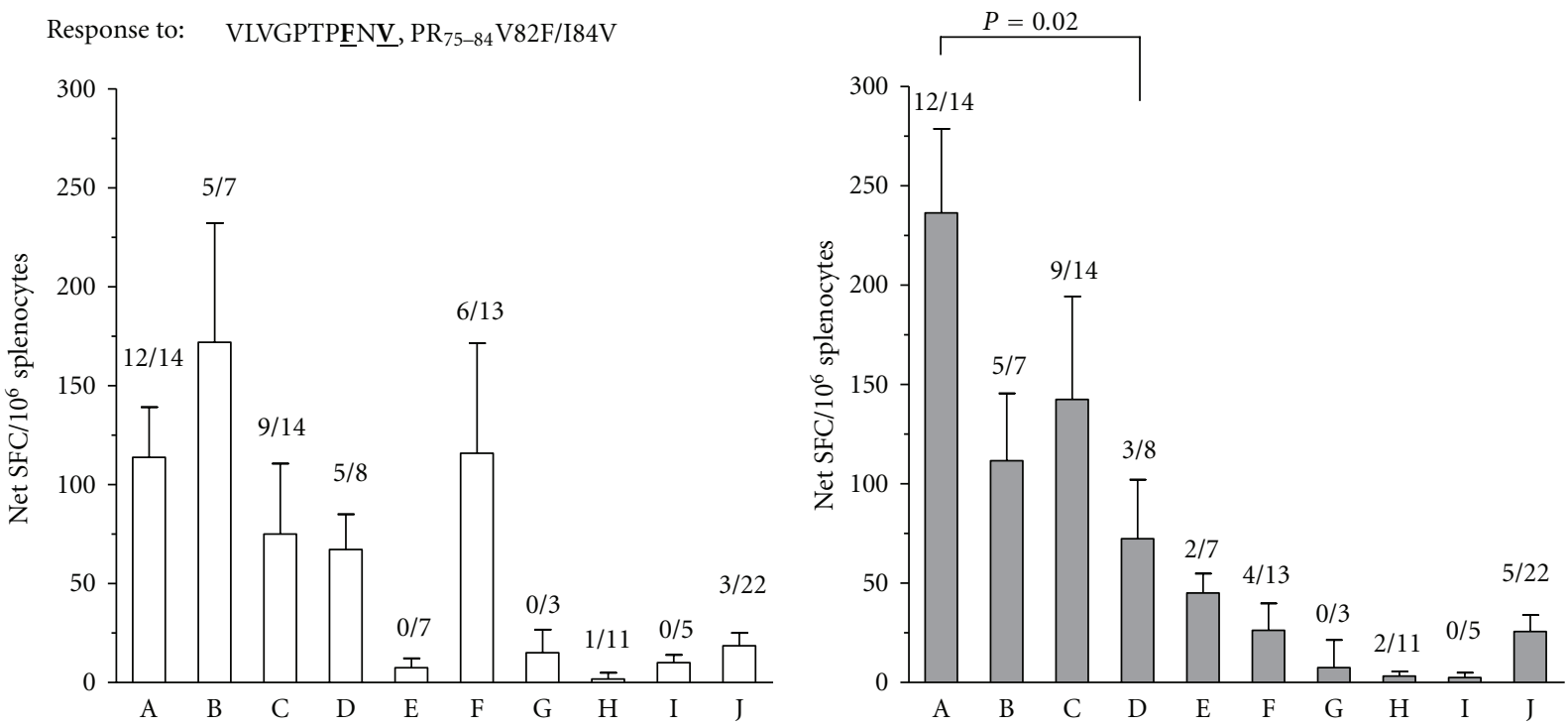

(b)

(c)

FIGURE 4: Specific immune responses to HIV $\mathrm{PR}_{75-84}$ peptide and variants harbouring drug-resistance mutations. Splenocytes were purified two weeks following the last immunization. The cells were stimulated over night with the (a) singly mutated (I84V), (b) doubly mutated (V82F/I84V), or (c) the wild-type peptide variants of $\mathrm{PR}_{75-84}$. Bars are showing the median response of the different groups. Specific responses were calculated by subtracting background responses to a control peptide from PR-specific immune responses. Proportion of responding animals ( $>50$ spot forming cells $/ 10^{6}$ splenocytes) are indicated above each individual bar.

of the HIV protease, and the CTB moiety retained the ability to form functional pentamers. The fusion protein that contained a 15 amino acid long epitope of HIV protease also induced a good but lower response. These two fusion proteins were found to bind with different affinity to GM1 and the binding correlated with immunogenicity. Taken together, our results show that peptides from HIV fused to CTB in a manner that allows pentamerization of the protein augments the cellular immune response to the epitope. This concept may be used to induce high and durable cellular immune responses against epitope antigens.

\section{Conflict of Interests}

All authors declare that they have no conflict of interests. 


\section{Acknowledgments}

The authors would like to thank PhD Susanne Johansson for her assistance in statistical analysis. This work was financially supported by grants from the Europrise program HIV Vaccines and Microbicides, Swedish physicians against AIDS research foundation, the Swedish Research Council, the Swedish Agency for Innovation Systems, and Cancer and Allergy foundation. The founders were not involved in study setup, data interpretation, or finalization of the article.

\section{References}

[1] S. G. Deeks, "Transmitted minority drug-resistant HIV variants: a new epidemic?” PLoS Medicine, vol. 5, no. 7, p. e164, 2008.

[2] V. Tozzi, A. Corpolongo, R. Bellagamba, and P. Narciso, "Managing patients with sexual transmission of drug-resistant HIV," Sexual Health, vol. 2, no. 3, pp. 135-142, 2005.

[3] D. Turner and M. A. Wainberg, "HIV transmission and primary drug resistance," AIDS Reviews, vol. 8, no. 1, pp. 17-23, 2006.

[4] C. A. B. Boucher, A. M. J. Wensing, R. Schuurman, D. A. M. C. van de Vijver, A. I. Stolwijk, and M. Toet, "Transmission of drug-resistant HIV-1 in Europe remains limited to single classes," AIDS, vol. 22, no. 5, pp. 625-635, 2008.

[5] A. M. J. Wensing, D. A. van de Vijver, G. Angarano, B. Asjo, C. Balotta, E. Boeri et al., "Prevalence of drug-resistant HIV-1 variants in untreated individuals in Europe: implications for clinical management," The Journal of Infectious Diseases, vol. 192, no. 6, pp. 958-966, 2005.

[6] A. Boberg, S. Dominici, A. Brave et al., "Immunization with HIV protease peptides linked to syngeneic erythrocytes," Infectious Agents and Cancer, vol. 2, article 9, 2007.

[7] A. Boberg, D. Sjöstrand, E. Rollman, J. Hinkula, B. Zuber, and B. Wahren, "Immunological cross-reactivity against a drug mutated HIV-1 protease epitope after DNA multi-CTL epitope construct immunization," Vaccine, vol. 24, no. 21, pp. 4527-4530, 2006.

[8] A. Boberg and M. Isaguliants, "Vaccination against drug resistance in HIV infection," Expert Review of Vaccines, vol. 7, no. 1, pp. 131-145, 2008.

[9] A. Boberg, S. Gaunitz, A. Bråve, B. Wahren, and N. Carlin, "Enhancement of epitope-specific cellular immune responses by immunization with HIV-1 peptides genetically conjugated to the B-subunit of recombinant cholera toxin," Vaccine, vol. 26, no. 40, pp. 5079-5082, 2008.

[10] C. Czerkinsky, M. W. Russell, N. Lycke, M. Lindblad, and J. Holmgren, "Oral administration of a streptococcal antigen coupled to cholera toxin B subunit evokes strong antibody responses in salivary glands and extramucosal tissues," Infection and Immunity, vol. 57, no. 4, pp. 1072-1077, 1989.

[11] J. Holmgren, J. Adamsson, F. Anjuère et al., "Mucosal adjuvants and anti-infection and anti-immunopathology vaccines based on cholera toxin, cholera toxin B subunit and $\mathrm{CpG}$ DNA," Immunology Letters, vol. 97, no. 2, pp. 181-188, 2005.

[12] M. Lebens, J. B. Sun, H. Sadeghi et al., "A mucosally administered recombinant fusion protein vaccine against schistosomiasis protecting against immunopathology and infection," Vaccine, vol. 21, no. 5-6, pp. 514-520, 2003.

[13] B. T. M. Korber, C. Brander, B. F. Haynes, R. Koup, J. P. Moore, B. D. Walker et al., HIV Molecular Immunology 2006/2007,
Los Alamos National Laboratory, Theoretical Biology and Biophysics, Los Alamos, New Mexico, 2007.

[14] A. C. Karlsson, J. M. Chapman, B. D. Heiken et al., "Antiretroviral drug therapy alters the profile of human immunodeficiency virus type 1-specific T-cell responses and shifts the immunodominant cytotoxic T-lymphocyte response from Gag to Pol," Journal of Virology, vol. 81, no. 20, pp. 1154311548, 2007.

[15] A. C. Karlsson, S. G. Deeks, J. D. Barbour et al., "Dual pressure from antiretroviral therapy and cell-mediated immune response on the human immunodeficiency virus type 1 protease gene," Journal of Virology, vol. 77, no. 12, pp. 6743-6752, 2003.

[16] M. Lebens, S. Johansson, J. Osek, M. Lindblad, and J. Holmgren, "Large-scale production of Vibrio cholerae toxin B subunit for use in oral vaccines," Nature Biotechnology, vol. 11, no. 13, pp. 1574-1578, 1993.

[17] D. Eisenberg, R. M. Weiss, and T. C. Terwilliger, "The hydrophobic moment detects periodicity in protein hydrophobicity," Proceedings of the National Academy of Sciences of the United States of America, vol. 81, no. 1, pp. 140-144, 1984.

[18] S. Pascolo, N. Bervas, J. M. Ure, A. G. Smith, F. A. Lemonnier, and B. Pérarnau, "HLA-A2.1-restricted education and cytolytic activity of $\mathrm{CD}^{+} \mathrm{T}$ lymphocytes from $\beta 2$ microglobulin $(\beta 2 \mathrm{~m})$ HLA-A2.1 monochain transgenic $\mathrm{H}-2 \mathrm{D}^{b} \beta 2 \mathrm{~m}$ double knockout mice," The Journal of Experimental Medicine, vol. 185, no. 12, pp. 2043-2051, 1997.

[19] P. Borrow, H. Lewicki, B. H. Hahn, G. M. Shaw, and M. B. A. Oldstone, "Virus-specific $\mathrm{CD}^{+}$cytotoxic T-lymphocyte activity associated with control of viremia in primary human immunodeficiency virus type 1 infection," Journal of Virology, vol. 68, no. 9, pp. 6103-6110, 1994.

[20] R. A. Koup, J. T. Safrit, Y. Cao et al., “Temporal association of cellular immune responses with the initial control of viremia in primary human immunodeficiency virus type 1 syndrome," Journal of Virology, vol. 68, no. 7, pp. 4650-4655, 1994.

[21] J. T. Safrit, C. A. Andrews, T. Zhu, D. D. Ho, and R. A. Koup, "Characterization of human immunodeficiency virus type 1specific cytotoxic $\mathrm{T}$ lymphocyte clones isolated during acute seroconversion: recognition of autologous virus sequences within a conserved immunodominant epitope," The Journal of Experimental Medicine, vol. 179, no. 2, pp. 463-472, 1994.

[22] J. E. Schmitz, M. J. Kuroda, S. Santra et al., "Control of viremia in simian immunodeficiency virus infection by $\mathrm{CD} 8^{+}$lymphocytes," Science, vol. 283, no. 5403, pp. 857-860, 1999.

[23] B. Julg, K. L. Williams, S. Reddy et al., "Enhanced anti-HIV functional activity associated with Gag-specific CD8 T-cell responses," Journal of Virology, vol. 84, no. 11, pp. 5540-5549, 2010.

[24] P. Kiepiela, K. Ngumbela, C. Thobakgale et al., "CD8 ${ }^{+}$T-cell responses to different HIV proteins have discordant associations with viral load," Nature Medicine, vol. 13, no. 1, pp. 4653, 2007.

[25] K. Eriksson, M. Fredriksson, I. Nordström, and J. Holmgren, "Cholera toxin and its B subunit promote dendritic cell vaccination with different influences on Th1 and Th2 development," Infection and Immunity, vol. 71, no. 4, pp. 1740-1747, 2003.

[26] A. George-Chandy, K. Eriksson, M. Lebens, I. Nordström, E. Schön, and J. Holmgren, "Cholera toxin B subunit as a carrier molecule promotes antigen presentation and increases CD40 and CD86 expression on antigen-presenting cells," Infection and Immunity, vol. 69, no. 9, pp. 5716-5725, 2001. 
[27] K. Badizadegan, H. E. Wheeler, Y. Fujinaga, and W. I. Lencer, "Trafficking of cholera toxin-ganglioside GM1 complex into Golgi and induction of toxicity depend on actin cytoskeleton," American Journal of Physiology, vol. 287, no. 5, pp. C1453C1462, 2004.

[28] P. I. H. Bastiaens, I. V. Majoul, P. J. Verveer, H. D. Söling, and T. M. Jovin, "Imaging the intracellular trafficking and state of the AB5 quaternary structure of cholera toxin," The EMBO Journal, vol. 15, no. 16, pp. 4246-4253, 1996.

[29] Y. Fujinaga, A. A. Wolf, C. Rodighiero et al., "Gangliosides that associate with lipid rafts mediate transport of cholera and related toxins from the plasma membrane to endoplasmic reticulm," Molecular Biology of the Cell, vol. 14, no. 12, pp. 47834793, 2003.

[30] J. Holmgren, N. Lycke, and C. Czerkinsky, "Cholera toxin and cholera B subunit as oral-mucosal adjuvant and antigen vector systems," Vaccine, vol. 11, no. 12, pp. 1179-1184, 1993.

[31] N. Lycke, "From toxin to adjuvant: basic mechanisms for the control of mucosal IgA immunity and tolerance," Immunology Letters, vol. 97, no. 2, pp. 193-198, 2005.

[32] J. Nikolic-Zugic and F. R. Carbone, "Peptide presentation by class-I major histocompatibility complex molecules," Immunologic Research, vol. 10, no. 1, pp. 54-65, 1991. 

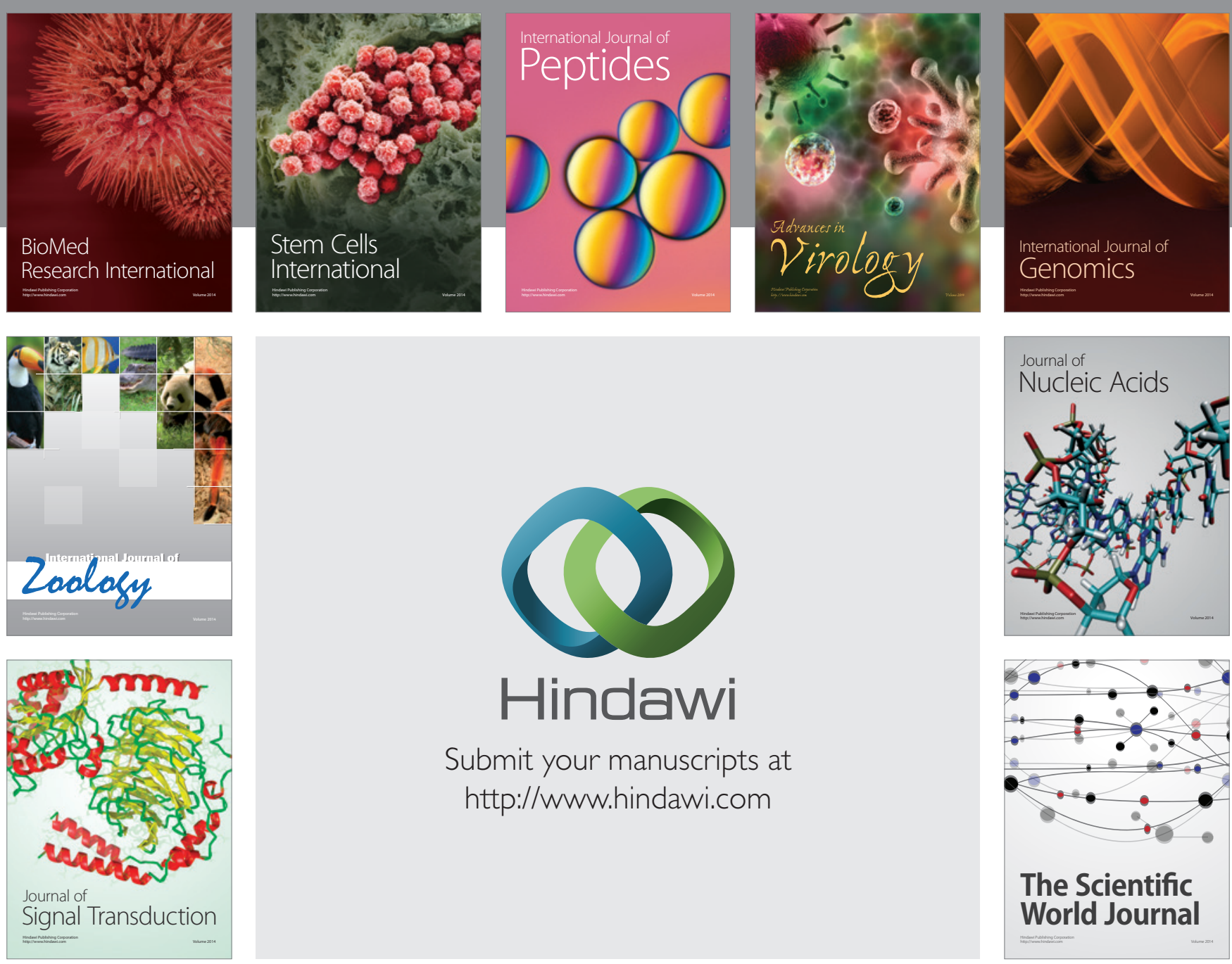

Submit your manuscripts at

http://www.hindawi.com
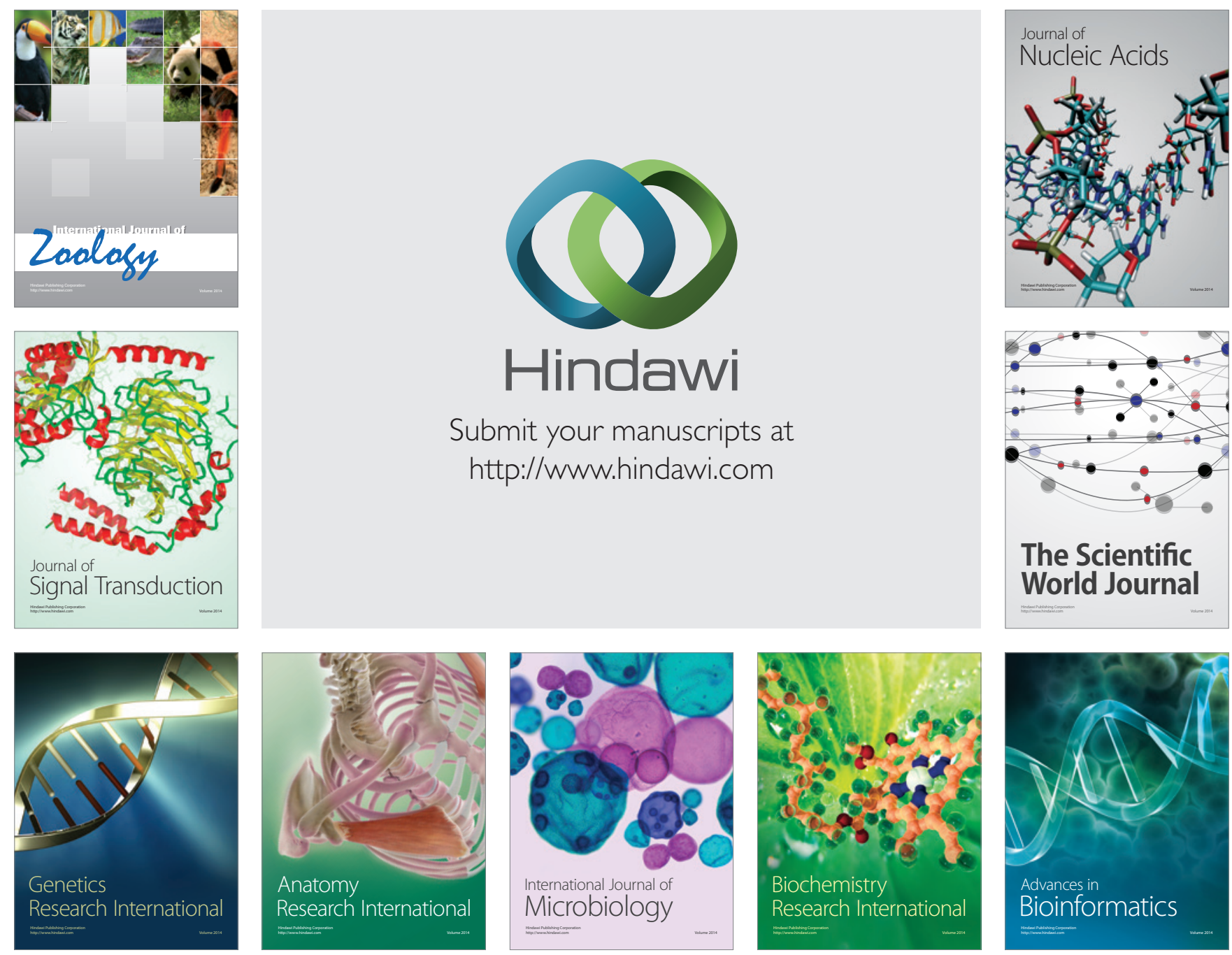

The Scientific World Journal
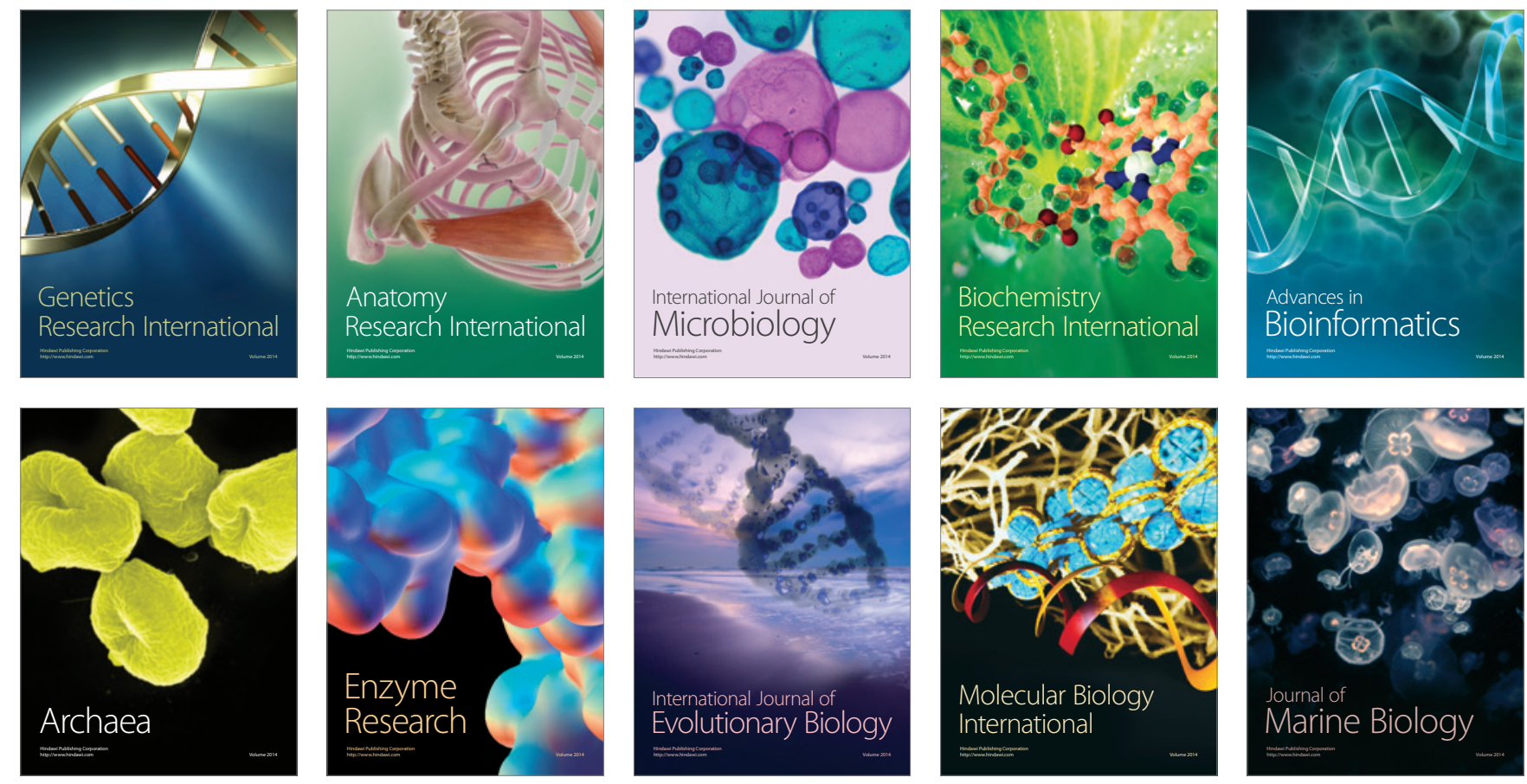